\title{
Evaluation of Some Anionic Exchange Resins as Potential Tablet Disintegrants
}

\author{
Prasert Akkaramongkolporn*, Nistakan Pattarakan, Praneet Opanasopit, \\ Tanasait Ngawhirunpat and Theerasak Rojanarata
}

Pharmaceutical Development of Green Innovations Group (PDGIG), Faculty of Pharmacy, Silpakorn University, Nakhon Pathom, Thailand

*For correspondence: Email: prasert@su.ac.th; Tel: (66) 34-255800; Fax: (66) 34-255941

\begin{abstract}
Purpose: To determine the potential of some anionic exchange resins as tablet disintegrants. Methods: Dowex $1 \circledR \times 2, x 4$ and $x 8$ resins (crosslinked copolymers of styrene and divinylbenzene with quaternary methyl amine functionality) were evaluated as disintegrant for dibasic calcium phosphate dihydrate tablets. The best resin providing the fastest disintegration and highest hardness of obtained tablets was selected for further investigation. The effect of resin concentration and compression force on the properties of tablets using the selected resin was investigated. In addition, the disintegrant efficacy of the selected resin in the tablet formulations containing either a basic drug, e.g., dextromethorphan hydrobromide (DMP), or an acidic drug, e.g., diclofenac sodium (DCN), was determined in comparison with sodium starch glycolate (SSG).

Results: Dowex $1 \circledR x 2$ resin exhibited the fastest disintegration (6.0 s) and the highest hardness (103.6 $N)$ of obtained tablets. These disintegrating and tablet properties depended upon the resin concentration and compression force. For DMP, the resin provided faster disintegration and drug release (8.0 $\mathrm{s}$ and $100.4 \%$ at $10 \mathrm{~min}$ ) as compared with SSG $(16.2 \mathrm{~s}$ and $98.9 \%$ at $30 \mathrm{~min})$. In contrast, the resin caused the depleted release of DCN $(61.6 \%$ at $120 \mathrm{~min})$ in spite of providing the faster tablet disintegration (10.0 s) than SSG (15.5s) due to the ionic binding of the drug and resin. Conclusion: The Dowex1®x2 resin was shown to be a potential disintegrant for the tablets of basic drugs.
\end{abstract}

Keywords: Anionic exchange resin, Disintegrant, Dextromethorphan hydrobromide, Diclofenac sodium, Calcium phosphate

Tropical Journal of Pharmaceutical Research is indexed by Science Citation Index (SciSearch), Scopus, International Pharmaceutical Abstract, Chemical Abstracts, Embase, Index Copernicus, EBSCO, African Index Medicus, JournalSeek, Journal Citation Reports/Science Edition, Directory of Open Access Journals (DOAJ), African Journal Online, Bioline International, Open-J-Gate and Pharmacy Abstracts

\section{INTRODUCTION}

Disintegrant is an essential part in the tablet formulation which mostly, unless a proper disintegrant is added, will not disintegrate within the limited time interval specified in the pharmacopoeia [1]. The use of disintegrant will facilitate the disintegration of tablet into fine fractions by overcoming the cohesive strength introduced by compaction force and binder.
Consequently, this enhances the surface area of drug in contact with the aqueous environment for a more rapid release and hence bioavailability of drug $[1,2]$. From literature, the most common mechanisms by which a disintegrant acts to break up a tablet are swelling and wicking (capillary) $[3,4]$. Other mechanisms that may play a role in particular cases of tablet disintegration include deformation recovery, heat of wetting and the evolution of gas [1]. 
Starches, clays, gums and hydrophilic cellulosic polymers have historically been used as disintegrants in tablet formulation [3]. However, at the required amounts, these traditional disintegrants individually have certain drawbacks that have limited their widespread use. To this regard, a new group of disintegrants, referred to as "superdisintegrants", has been developed. Several materials proven to be superdisintegrants are sodium starch glycolate (modified starch), croscarmellose sodium (crosslinked cellulose), crospovidone (crosslinked polyvinylpyrrolidone) and polacrilin potassium (cationic exchange resin) [3-6].

An ion exchange resin is an insoluble crosslinked copolymer that possesses ionizable groups. The ionizable groups make the resin capable of hydration and swelling in an aqueous fluid [7]. Therefore, ion exchange resins have been exploited as effective disintegrants in tablet formulation [5,6], in addition to other diverse applications $[8,9]$. Nonetheless, this disintegrant application has been limited to only a cationic exchange resin derived from crosslinked methacrylic acid and divinylbenzene copolymer in a potassium salt form, i.e. polacrilin potassium (Amberlite IRP88®, Indion 294® and Tulsion $339 \circledast$ ) [5]. Therefore, the goal of this work was to expand such interesting applications to anionic exchange resins, which, to the best of our knowledge, has never been reported.

\section{EXPERIMENTAL}

\section{Materials}

Employed chemicals were purchased from various sources; Dowex1® x2, x4, x8 (200 mesh, Dow Chemical Company, USA), Dextromethorphan hydrobromide (Sigma Aldrich, USA), Diclofenac sodium (Sigma Aldrich, USA), Sodium starch glycolate (Explotab®, JRS Pharma, Germany), Dibasic calcium phosphate dihydrate (Emcompress $®$, JRS Pharma, Germany), spray-dried rice starch (Era-Tab®, Erawan Pharmaceutical Research and Laboratory, Thailand), spray-dried lactose (Super-Tab 11SD ${ }^{\circledR}$, DFE Pharma, Germany), microcrystalline cellulose (Avicel PH102®, FMC Corporation, USA.), magnesium stearate (Mallinckrodt Inc., USA). The remainder of chemicals was at least analytical grade and deionized water was entirely used in this work.

\section{Characterization of resins}

All resins were dried in a hot air oven at $60{ }^{\circ} \mathrm{C}$ for $2 \mathrm{~h}$ before characterization and use. The average diameter of each resin was determined from measuring 200 resin particles under a microscope (CX41, Olympus, Japan) at the proper magnification.

The hydration of resins was determined in triplicate by the following procedure, which was modified from previous work [10]. An accurate weight $(300 \mathrm{mg})$ of each resin, recorded as the initial weight (wi), was placed in a $1.5 \mathrm{~mL}$ microcentrifuge tube. Next, $1 \mathrm{~mL}$ of deionized water was added into the microcentrifuge tube and left for hydration for $2 \mathrm{~h}$. Thereafter, the microcentrifuge tube was centrifuged at 2,000 rpm for $3 \mathrm{~min}$, and the supernatant was then removed. The hydrated resin was weighed (wh), and the hydration of resin was calculated as in Eq 1.

Hydration $(\%)=\{(w h-w i) / w i\} 100$.

The swellability of the resins was determined in triplicate as follows [11]. One gram of sample was weighed and placed in a $10 \mathrm{~mL}$ cylinder, which was tapped to constant volume (vi). An excess amount of deionized water was added to the cylinder, and $2 \mathrm{~h}$ later, the volume of the swollen resin (vs) was recorded. The swelling (\%) of the resins was calculated using Eq 2.

Swelling $(\%)=\{(v s-v i) / v i\} 100$.

\section{Formulation and evaluation of DCP tablets}

Tablets with a constant weight $(500 \mathrm{mg})$ were made from dibasic calcium phosphate dihydrate (DCP) using $5 \%$ of each resin as a disintegrant and $1 \%$ of magnesium stearate as a lubricant. The DCP and a resin were blended for $3 \mathrm{~min}$, magnesium stearate was added, and the mixture was blended further for $2 \mathrm{~min}$. Then, an accurately weighed mixture was placed into a hydraulic hand press machine (Specac P/N 15011/25011, UK), and compressed using stainless steel flat-circular punches $(9.3 \mathrm{~mm}$ in diameter) with a constant force of 4.5 ton. The produced tablets were characterized for their thickness, diameter, hardness and disintegration time. From this study, the best resin in terms of tablet properties, i.e. the shortest disintegration time and highest hardness, was selected for further investigation.

\section{Evaluation of disintegrant properties}

The effect of resin concentration and compression force on the properties of the tablets using the selected resin as a disintegrant was investigated. The tablets were made from DCP using various concentrations of the resin, i.e., 2.5, 5.0, 7.5 and $10 \% \mathrm{w} / \mathrm{w}$, and compression 
forces, i.e. $0.5,1.5,3.0$ and 4.5 tons, respectively. Other variables were kept constant, and the remaining procedures were the same as described above. The thickness, diameter, hardness and disintegration time of the obtained tablets were determined.

\section{Evaluation of factors affecting DCP tablet properties}

Dextromethorphan hydrobromide (DMP) and diclofenac sodium (DCN) were chosen as representatives of basic and acidic model drugs, respectively, to monitor the effect of charge on drug release. Each tablet $(500 \mathrm{mg})$ made from DCP contained $15 \mathrm{mg}$ of DMP or $25 \mathrm{mg}$ of DCN, $1 \%$ of magnesium stearate lubricant and $5 \%$ of the selected resin as a disintegrant, pressed at 4.5 tons of compression force. The remaining procedures and press machine used were identical to those described above. The produced tablets were characterized for their thickness, diameter, hardness, disintegration time and dissolution profile. For comparison, the formulation of DCP tablets using sodium starch glycolate (SSG) was also prepared and evaluated.

\section{Evaluation of tablet properties}

The thickness and hardness of ten tablets from each sample were characterized using a multifunctional tablet tester (Erweka TBH 225TD, Germany). The disintegration time was measured using a USP disintegration testing apparatus (Sotax DT3, Switzerland) [12] and conducted in deionized water at $37 \pm 1{ }^{\circ} \mathrm{C}$. The dissolution profile was examined for six tablets from each sample using a USP dissolution apparatus 2 (Pharma-Test, Germany) set at 50 rpm of paddle rotation. According to the pharmacopeia [12], the phosphate buffer solutions $\mathrm{pH} 5.8$ and $6.8(900 \mathrm{~mL})$ maintained at $37{ }^{\circ} \mathrm{C} \pm 0.5$ were used as dissolution media for the tablets containing DMP and DCN, respectively. The amount of released drug was determined by the HPLC method.

A HPLC with UV detection (Shimadzu SPD-10 AVP, Japan) set at the wavelengths of 254 and $280 \mathrm{~nm}$ was used for analyzing DMP and DCN, respectively. The analysis of both drugs employed the same column, i.e. a $4.6 \mathrm{~mm} \times 250$ mm ACE5 C18-AR (Advanced Chromatography Technology Ltd., UK). The mobile phase for analyzing DMP contained $0.007 \mathrm{M}$ docusate sodium and $0.007 \mathrm{M}$ ammonium nitrate in a mixture of acetonitrile and water (70:30) adjusted to $\mathrm{pH} 3.4$ with glacial acid, while that for analyzing DCP was a mixture $(70: 30)$ of methanol and phosphate buffer solution $\mathrm{pH} 2.5$ [12]. The retention times of DMP and DCN appeared at 6 and $21 \mathrm{~min}$, respectively.

\section{Statistical analysis}

Significant effect of variables on determined parameters was tested with one-way analysis of variance (ANOVA) and the least significant difference (LSD) test for multiple comparisons, run on an open source software, OpenStat. Differences were considered statistically significant at $p<0.05$.

\section{RESULTS}

Dowe $1 \AA \times 2, x 4$ and $x 8$ are strongly anionic exchange resins derived from styrene and divinylbenzene copolymer bearing the quaternary methyl amine as an ion exchangeable group (Fig 1). The number after the multiplication sign indicates the degree of copolymer crosslinking, which is determined from the percentage of divinylbenzene used as a crosslinker in the synthesis of the resins via polymerization [13]. In previous studies, these resins were pharmaceutically used as carriers for sustainedrelease drug delivery systems of acidic drugs e.g. diclofenac sodium [14,15]. The average diameters of Dowex1®x2, x4 and $x 8$ were measured to be 189.6, 171.3 and $190.7 \mu \mathrm{m}$, respectively. The hydration and swelling of the resins were in the rank order; Dowex $1 \circledast \times 2>x 4>$ x8 $(p<0.05)$, as depicted in Fig 2.

The determination of which resins $(5 \% \mathrm{w} / \mathrm{w})$ were potential disintegrants was evaluated using directly compressed tablets of DCP without therapeutic agents. DCP was chosen as the direct compression diluent because of its water insolubility and its lack of disintegrating property $[1,2]$. Due to these properties, the breaking of a DCP tablet primarily resulted from the disintegrating property of the resins. The properties of DCP tablets using various resins as disintegrants are presented in Table 1. The DCP tablets without resins did not disintegrate within $30 \mathrm{~min}(>1800 \mathrm{~s}$ ), but those containing Dowex $1 \circledast \times 2$ and $x 4$ rapidly disintegrated at 6.0 and $25.0 \mathrm{~s}$, respectively $(p<0.05)$. The longer disintegration time obtained from Dowex $1 \AA \times 4$ was in agreement with the lower ability for hydration and swelling of the resin (Fig 2). Dowe $1 \circledast \times 8$ provided much higher disintegration time of the DCP tablet, corresponding to its lowest ability for hydration and swelling. The DCP tablets containing the resins as disintegrants were softer and thicker than those without resins $(p<0.05)$. 




Figure 1: Chemical structure of Dowex $1^{\circledR}$ resin

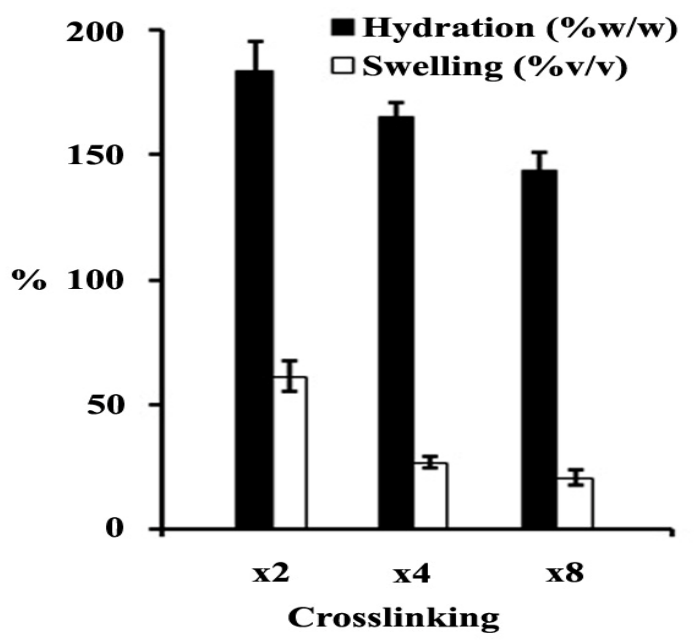

Figure 2: Hydration and swelling of Dowex $1^{\circledR}$ resins

From the above findings, Dowex $1 \circledR \times 2$ provided the fastest disintegration $(6.0 \mathrm{~s})$ and highest hardness $(103.6 \mathrm{~N})$ of the obtained tablets; as a result, it was selected as the anionic exchange resin disintegrant for further investigation. The effect of the concentration of Dowex1® $\times 2$ on the properties of DCP tablets pressed at 4.5 tons is presented in Table 2. The disintegration time of the DCP tablets was lowered with increasing the resin concentration up to $5.0 \%(p<0.05)$. However, the disintegration time became higher $(p<0.05)$ when the resin concentration was increased greater than $5.0 \%$. The increased concentration of resin resulted in the decreased hardness and increased thickness of DCP tablets $(p<0.05)$.

Table 3 presents the effect of compression pressure on the properties of the DCP tablets using $5 \% \mathrm{w} / \mathrm{w}$ of Dowex $1 \circledast \times 2$ as a disintegrant. The compression pressure significantly affected the properties i.e. thickness, hardness and disintegration time of DCP tablets using the resin disintegrant $(p<0.05)$.

The selected resin was also employed to formulate the DCP tablets containing therapeutic agents, i.e., DMP or DCN. The physical and drug release properties of the formulated tablets using Dowex $1 \circledast x 2$ in comparison with SSG are presented in Table 4 and Fig 3, respectively. The resin provided shorter disintegration times of the tablets for both drugs than did SSG $(p<0.05)$, proving that the resin was an effective disintegrant for the tablet formulations. Like SSG, the resin was similarly effective in breaking the DMP and DCN tablets $(p>0.05)$. For both drugs, the tablets using the resin disintegrant were softer and thicker than those using SSG $(p<$ 0.05).

Table 1: Properties of tablets containing various Dowex $1^{\circledR}$ resins

\begin{tabular}{llll}
\hline Resin & $\begin{array}{l}\text { Thickness } \\
(\mathbf{m m})\end{array}$ & $\begin{array}{l}\text { Hardness } \\
(\mathbf{N})\end{array}$ & $\begin{array}{l}\text { Disintegration } \\
\text { time }(\mathbf{s})\end{array}$ \\
\hline No resin & $3.21 \pm 0.03$ & $276.8 \pm 13.5$ & $>1800$ (almost intact) \\
Dowex $1{ }^{(B)} \times 2$ & $3.69 \pm 0.04$ & $103.6 \pm 4.8$ & $6.0 \pm 0.0$ \\
${\text { Dowex } 1{ }^{(B)} \times 4}^{(3)}$ & $4.01 \pm 0.11$ & $71.2 \pm 13.8$ & $25.0 \pm 5.2$ \\
Dowex $1{ }^{(\Theta)} \times 8$ & $4.03 \pm 0.12$ & $69.6 \pm 14.1$ & $>1800$ (partially \\
& & & disintegrate) \\
\hline
\end{tabular}

Table 2: Effect of resin concentration on properties of tablets containing Dowex $1{ }^{\circledR} \times 2$

\begin{tabular}{llll}
\hline $\begin{array}{l}\text { Concentration } \\
(\% \mathbf{w} / \mathbf{w})\end{array}$ & $\begin{array}{l}\text { Thickness } \\
(\mathbf{m m})\end{array}$ & $\begin{array}{l}\text { Hardness } \\
(\mathbf{N})\end{array}$ & $\begin{array}{l}\text { Disintegration } \\
\text { time }(\mathbf{s})\end{array}$ \\
\hline 0 & $3.21 \pm 0.03$ & $276.8 \pm 13.5$ & $>1800$ \\
2.5 & $3.51 \pm 0.03$ & $133.8 \pm 10.2$ & $146.9 \pm 11.7$ \\
5.0 & $3.69 \pm 0.04$ & $103.6 \pm 4.8$ & $6.0 \pm 0.0$ \\
7.5 & $3.88 \pm 0.02$ & $93.1 \pm 3.6$ & $12.5 \pm 1.6$ \\
10.0 & $3.97 \pm 0.05$ & $75.6 \pm 4.7$ & $10.0 \pm 0.0$ \\
\hline
\end{tabular}


Table 3: Effect of pressure on properties of tablets containing Dowex $1^{\circledR} \times 2$

\begin{tabular}{lccc}
\hline $\begin{array}{l}\text { Compression } \\
\text { pressure (ton) }\end{array}$ & Thickness $(\mathbf{m m})$ & Hardness (N) & Disintegration time (s) \\
\hline 0.5 & $4.11 \pm 0.02$ & $16.7 \pm 1.6$ & $26.8 \pm 1.1$ \\
1.5 & $3.79 \pm 0.02$ & $50.0 \pm 5.4$ & $8.5 \pm 0.5$ \\
3.0 & $3.64 \pm 0.04$ & $98.0 \pm 7.8$ & $7.5 \pm 0.5$ \\
4.5 & $3.69 \pm 0.04$ & $103.6 \pm 4.8$ & $6.0 \pm 0.0$ \\
\hline
\end{tabular}

Table 4: Properties of formulated tablets using Dowex $1^{\circledR} \mathrm{x} 2$ versus SSG

\begin{tabular}{llccc}
\hline Drug & Disintegrant & Thickness (mm) & Hardness (N) & $\begin{array}{c}\text { Disintegration } \\
\text { time (s) }\end{array}$ \\
\hline DMP & Dowex1 ${ }^{(\circledR)} \times 2$ & $3.73 \pm 0.02$ & $79.7 \pm 10.1$ & $8.0 \pm 1.0$ \\
& SSG & $3.46 \pm 0.02$ & $144.7 \pm 14.3$ & $16.2 \pm 0.4$ \\
DCN & & & & \\
& Dowex1 ${ }^{\circledR} \times 2$ & $3.39 \pm 0.02$ & $72.4 \pm 5.3$ & $10.0 \pm 1.6$ \\
& SSG & $3.15 \pm 0.01$ & $122.9 \pm 2.0$ & $15.5 \pm 0.5$ \\
\hline
\end{tabular}
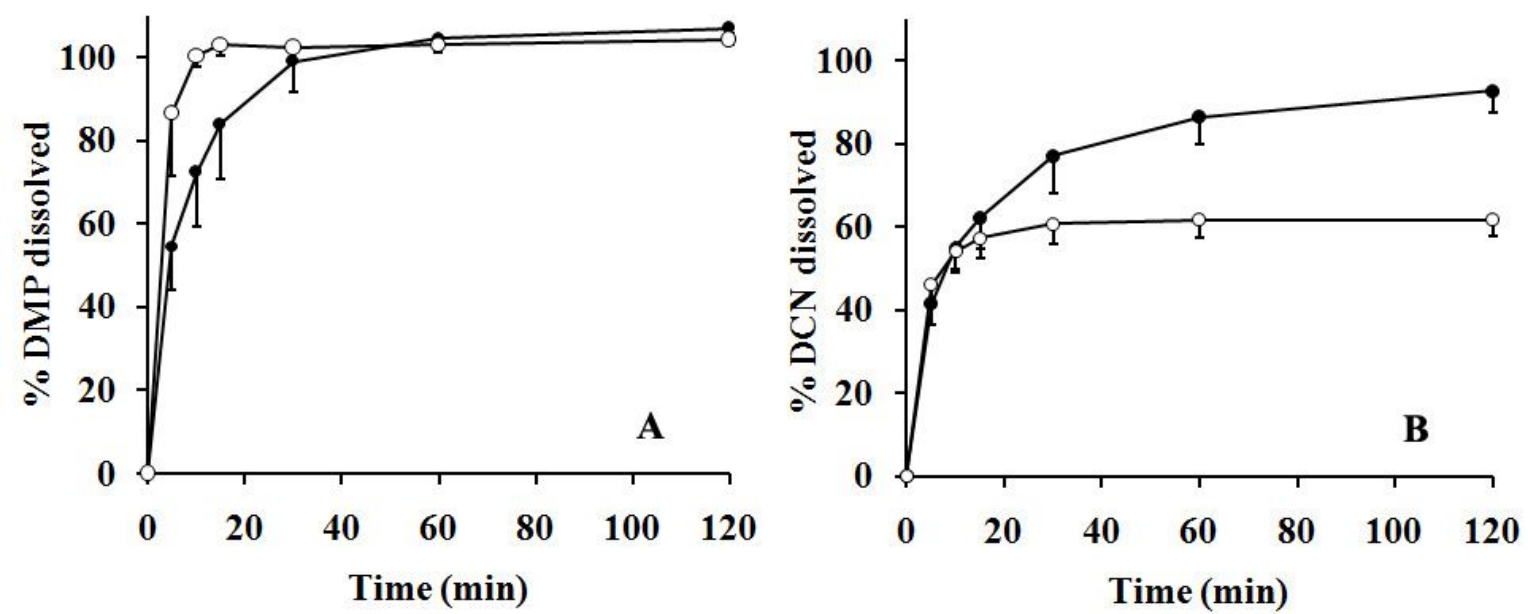

Figure 3: Dissolution profiles of DMP $(A)$ and DCN $(B)$ from DCP tablets using Dowex $1^{\circledR} \times 2(\circ)$ versus SSG $(\bullet)$

Compared with SSG, the resin disintegrant provided the faster DMP release (Fig 3A), which was in agreement with the shorter time required for tablet disintegration $(p<0.05)$ as presented in Table 4. As with DCN, at early times ( $\leq 15 \mathrm{~min}$ ), the tablet using the resin provided a drug release comparable to that of SSG (Fig 3B), even though it disintegrated faster $(p<0.05)$ as listed in Table 5 . Thereafter, the drug release from the tablet using the resin leveled off, whereas that using SSG proceeded further.

\section{DISCUSSION}

As shown in Fig 2, the resins exhibited the ability for hydration and swelling due to the presence of ion exchangeable groups [7]. In contact with water, these groups dissociated and formed a concentrated electrolyte solution within the resin.
The electrolyte solution generated osmotic activity and then induced the entry of water into the resins (hydration) along with the expansion of the resins (swelling). The higher crosslinked resin had a tougher matrix structure and hence more difficulty to expand, thus providing the less ability for hydration and swelling [7].

The DCP tablets containing Dowex $1 \circledR \times 2$ had the lowest disintegration time (Table 1), indicating that the resin was the most effective disintegrant. In the disintegrating process, the resin hydrated and swelled, causing the tablet to disintegrate, probably via the wicking and swelling actions. Since the degree of hydration was dramatically higher than swelling (Fig 2) the wicking action might predominantly cause the tablet disintegration. These mechanisms also accounted for the disintegrating property of polacrilin potassium, a cationic exchange resin 
practically usable as a disintegrant [5]. The longer disintegration time obtained from Dowex1®x4 and x8, respectively, were in agreement with the lower ability for hydration and swelling of the resins.

The resins, particularly with higher degrees of crosslinking, exhibited the lower compactibility compared with DCP, resulting in the lower hardness and the greater thickness of obtained tablets. As the crosslinking increased, the resin developed a tougher matrix structure [7] and perhaps a lower propensity for consolidation under compression. The DCP tablets containing Dowex $1 \AA \times 4$ and $\times 8$ were softer but disintegrated at a slower rate compared with the tablet containing Dowex $1 \circledast x 2$, which was harder. This finding confirmed that the tablet breakup was primarily caused by the disintegrating action of the resins rather than the reduction of hardness.

The effect of Dowex1®x2 concentration on the disintegration time of DCP tablets showed a reverse pattern (Table 2). The disintegration time was decreased with increasing the resin concentration up to $5 \%$, but was increased with increasing the resin concentration greater than 5 $\%$. This pattern is usually found for most disintegrants, which exhibits a limited concentration range for creating an efficient disintegration [3]. Outside of this limited range, not only can the disintegration time not be decreased, but it can also increase [16]. Due to the poor compactibility of the resin, the increased concentration of resin resulted in the softer and less-compact (i.e. thicker) tablet.

When the compression pressure was decreased from 4.5 to 0.5 tons, the disintegration time of DCP tablets containing Dowex $1 \circledast \times 2$ (5\% w/w) increased, while the tablet hardness decreased (Table 3). This finding coincided with a previous report, in which polacrilin postassium (Amberlite IRP88®) was used as a disintegant for a directly compressed tablet made from DCP [17]. When the pressure is lowered, the particles tend not to consolidate, thus resulting in a softer tablet with a relatively coarser pore size $[18,19]$. This effect can be seen by the increased thickness of the tablet (Table 3). As the hardness of the tablet decreases, the time taken for the entry of the fluid and swelling of the resin with subsequent tablet disintegration decreases through an increase in porosity $[10,19]$. Under this condition, however, the resin cannot exert enough swelling force in such an enlarged pore to produce an immediate disintegration of the tablet [17]. In this case, the latter effect was predominant, thus causing the increased disintegration time with the decrease in the compression pressure.
No matter which drugs were incorporated, the tablets using Dowex1®x2 were softer and thicker than those using SSG (Table 4), implying that the resin exhibited lower compactability than SSG. The difference in compactibility can be ascribable to the different properties of the resin and SSG, e.g. the chemistry and size of the materials. SSG is the sodium salt of a starch derivative, of which the skeletal structure is analogous to a variety of directly compressible cellulosic materials, e.g. MCC [20], hydroxypropylmethylcellulose (HPMC) [21] and ethylcellulose (EC) [18]. In contrast, the resin is derived from the crosslinked copolymer of styrene and divinylbenzene (Fig 1), which was less compactible than HPMC and EC [11]. Further, SSG had the average size of $50-60 \mu \mathrm{m}$ [22], while the resin had the average size of $189.6 \mu \mathrm{m}$. Regarding the size difference, SSG particles with the more effective surface area are able to undergo greater consolidation and better encapsulation with other compositions during compression under pressure [10], thus displaying more compactibility. When using the same disintegrant, the tablet containing DMP resulted in a greater thickness than DCN $(p<0.05)$. Because the tablet of DMP was stronger than that of DCN, the thicker tablet containing DMP was probably due to the lower true density of DMP [23].

The resin disintegrant provided a superior rate of DMP release (Fig 3A) because of its shorter time required for tablet disintegration (Table 4). The faster tablet disintegration generally results in the faster drug dissolution due to the earlier exposure of the drug particles with the dissolution fluid [2]. However, the resin caused the lower DCN release in spite of providing the shorter disintegration time than SSG. A possible cause for the lower drug release obtained from the tablet using the resin can be explained by the binding of DCN and the resin during the testing of drug dissolution, referred to as resinate salt formation [24]. In the dissolution medium $\mathrm{pH} 6.8$, DCN (pKa = 4.0) [25] dissociated and was in anionic species, which enabled it to bind to the resin via anionic exchange reaction (Eqn 3), consequently lowering the drug release. Because of charge repulsion, however, this binding did not occur with DMP (pKa = 8.3) [26], which, in the dissolution medium $\mathrm{pH} 5.8$, was protonated to be the same cationic species as the resin.

$\mathrm{RCH}_{2}\left(\mathrm{CH}_{3}\right)_{3} \mathrm{~N}^{+} \mathrm{Cl}^{-}+\mathrm{DCN}^{-} \leftrightarrow \mathrm{RCH}_{2}\left(\mathrm{CH}_{3}\right)_{3} \mathrm{~N}^{+} \mathrm{DCN}^{-}+\mathrm{Cl}^{-} \ldots . .(3)$

\section{CONCLUSION}

The low crosslinked anionic exchange resin Dowex1巴x2 can act as a disintegrant due to its high ability for hydration and swelling. The 
mechanism of disintegration appears to be governed by wicking and swelling actions, similar to its counterpart: cationic exchange resin, i.e. polacrilin potassium. When manufactured using the proper levels of resin concentration and compression force, both the rapid disintegration and satisfactory hardness of the tablets formulated with the resin disintegrant can be obtained. This resin is exclusively suggested as a potential disintegrant for tablet formulations of basic drugs to avoid the ionic binding of the resin and drug that may deplete drug release.

\section{ACKNOWLEDGEMENT}

The authors thank Silpakorn University Research and Development Institute for funding this research (Grant No. SURDI 55/02/2555), and Faculty of Pharmacy, Silpakorn University, Nakhon Pathom, Thailand for instrumental support.

\section{REFERENCES}

1. Rudnic EM, Kottke MK. Tablet dosage forms. In: Banker SG, Rhodes CT, editors. Modern Pharmaceutics Third Edition, Revised and Expanded. New York: Marcel Dekker; 1996; pp 333-394.

2. Zhao N, Augsburger LL. Functionality comparison of 3 classes of superdisintegrants in promoting aspirin tablet disintegration and dissolution. AAPS PharmSciTech 2005; 6: E634-640.

3. Peck GE, Baley GJ, McCurdy VE, Banker GS. Tablet formulation and design. In: Lieberman HA, Lachman L, Schwartz JB, editors. Pharmaceutical Dosage Forms: Tablet, Vol. 1, Second Edition, Revised and Expanded. New York: Marcel Dekker; 1989; pp 75130.

4. Goyanes A, Souto C, Martíinez-Pacheco R. A comparison of chitosan-silica and sodium starch glycolate as disintegrants for spheronized extruded microcrystalline cellulose pellets. Drug Dev Ind Pharm 2011; 37: 825-831.

5. Bele MH, Derle DV. Effect of sorbed water on disintegrant performance of four brands of polacrilin potassium NF. AAPS PharmSciTech 2012; 13: 24-34.

6. Khan KA, Rhodes CT. Water-sorption properties of tablet disintegrations. J Pharm Sci 1975; 64: 447-451.

7. Harland CE. Ion Exchange: Theory and Practice. London: The Royal Society of Chemistry; 1994; p 285.

8. Borodkin S. Ion exchange resins and sustained release. In: Swarbick J, Boylan JC, editors. Encyclopedia of Pharmaceutical Technology, Vol. 8. New York: Marcel Dekker; 1993; pp 203-216.

9. Zeng HX, Wang M, Jia F, Lin SJ, Cheng G, Pan WS. Preparation and in vitro release of dual-drug resinate complexes containing codeine and chlorpheniramine. Drug Dev Ind Pharm 2011; 37: 201-207.
10. Adebayo SA, Brown-Myrie E, Itiola OA. Comparative disintegrant activities of breadfruit starch and official corn starch. Powder Technol 2008; 181: 98-103.

11. Akkaramongkolporn $P$, Ngawhirunpat $T$, Nunthanid J, Opanasopit $P$. Effect of a pharmaceutical cationic exchange resin on the properties of controlled release diphenhydramine hydrochloride matrices using Methocel K4M or Ethocel $7 c P$ as matrix formers. AAPS PharmSciTech 2008; 9: 899-908.

12. The United State Pharmacopoeia 29. Rockville MD: United State Pharmacopoeial Convention; 2006.

13. Russel P. An Introduction to lon-Exchange Resin. London: Heyden\&Son Ltd.; 1970.

14. Torres D, Seijo B, Garcia-Encina G, Alonso MJ, Vila-Jato JL. Microencapsulation of ion-exchange resins by interfacial nylon polymerization. Int J Pharm 1990; 59: 9-17.

15. Ichikawa H, Fujioka K, Adeyeye MC, Fukumori Y. Use of ion-exchange resins to prepare $100 \square m$-sized microcapsules with prolonged drug-release by the Wurster process. Int J Pharm 2001; 216: 67-76.

16. Ferrero C, Munoz N, Velasco MV, Munoz-Ruiz A, Jimenez-castellanos $R$. Disintegrating efficiency of croscarmellose sodium in a direct compression formulation. Int J Pharm 1997; 147: 11-21.

17. Khan KA, Rhodes CT. Disintegration properties of calcium phosphate dibasic dihydrate tablets. J Pharm Sci 1975; 64: 166-168.

18. Dabbagh MA, Ford JL, Rubinstein MH. Effects of polymer particle size, compaction pressure and hydrophilic polymers on drug release from matrices containing ethylcellulose. Int J Pharm 1996; 140: 85-95.

19. Riippi M, Antikainen O, Niskanen T, Yliruusi J. The effect of compression force on surface structure, crushing strength, friability and disintegration time of erythromycin acistrate tablets. Eur J Pharm Biopharm 1998; 46: 339-345.

20. Bolhuis GK, Chowhan ZT. Materials for direct compression. In: Alderborn G, Nystrom C, editors. Pharmaceutical Powder Compression Technology. New York: Marcel Dekker; 1996; pp 419-500.

21. Nokhodchi A, Rubinstein MH, Ford JL. The effect of particle size and viscosity grade on the compaction properties of hydroxypropylmethylcellulose 2208. Int J Pharm 1995; 126: 189-197.

22. Edge S, Belu AM, Potter UJ, Steele DF, Young PM, Price $R$, Staniforth JN. Chemical characterization of sodium starch glycolate particles. Int J Pharm 2002; 240: 6778.

23. Chemnet Global Chemical Network: [cited 2013 June 26]. Available from http://www.chemnet.com/cas/.

24. Sriwongjanya $M$, Bodmeier $R$. Effect of ion exchange resins on the drug release from matrix tablets. Eur $J$ Pharm Biopharm 1998; 46: 321-327.

25. Khazaeinia T, Jamali F. A comparison of gastrointestinal permeability induced by diclofenac-phospholipid complex with diclofenac acid and its sodium salt. $J$ Pharm Pharmaceut Sci 2003; 6: 352-359.

Trop J Pharm Res, October 2014; 13(10): 1591 
Akkaramongkolporn et al

26. Borodkin S, Yunker MH. Interaction of amine drugs with a polycarboxylic acid ion-exchange resin. J Pharm Sci
1970; 59: 481-486. 